\title{
Non-Groningen gas supplies for Western Europe
}

\section{P. Mellbye}

Executive Vice President, Statoil.

The sustained growth in natural gas demand in Western Europe is foreseen to persist throughout the next decades. Producers will seek to match the natural gas demand growth by developing their considerable untapped natural gas resources. However, as uncommitted mature resources start to dwindle, likely candidates to match the long-term natural gas demand growth are increasingly further away from the market. The ultimate consequence is increasing long-term marginal supply costs to the market, not only in terms of transportation costs due to increased distances, but also in terms of development and exploitation costs in frontier regions.

Producers have traditionally required long-term guarantees in order to ensure recovery of their capital costs. Considerable investments are required to develop natural gas resources and deliver these to the market. This guarantee has traditionally been provided through the so-called take or pay (TOP) mechanism in the natural gas sales contracts. In the traditional gas contracts the natural gas price is indexed against the price of substitute sources of energy (to a large extent crude oil or oil products). These contracts allocate the volume risk to the purchasing companies in the market and the price risk to the producers.

However, the prevailing energy prices (particularly those of crude oil) are hardly enticing for the development of high risk natural gas resources.
The enactment of the EU Gas Directive induces a legislative framework, that complicates the establishment of TOP sales contracts, which have served to mitigate the producer's risk inherent to the development of natural gas resources. The development of further supply projects to the market will of course be determined by economic considerations, as part of the producers finding the right balance between risks and rewards remains the central issue.

The presently prevailing expectations of low energy prices and potential increases in volume risk, as a consequence of the process of deregulation, may lead to a long term market equilibrium at a lower level of natural gas demand than what we like to project.

The development of resources on the Norwegian Continental Shelf (NCS) is also influenced by the aforementioned environment. However, the NCS displays a well integrated transport system which will provide a firm basis for the tapping of the region's recourses.

Lower prices and higher risks will shift the focus from developing new frontier areas to smaller finds closer to existing infrastructures. A consequence will be falling Reserves/Production ratios and potential questions as to long term security of supply. 